\title{
A Humanistic Understanding of Persons as a Prerequisite for Person-Centeredness
}

\author{
Peter Heusser ${ }^{a, c}$ Johannes Weinzirl ${ }^{a, c}$ Rene Ebersbach ${ }^{a, c}$ Bettina Berger ${ }^{b, c} \quad$ Ulrich Weger ${ }^{c, d}$ \\ Arndt Büssing ${ }^{c, e}$ Martina Schwiegershausen ${ }^{a, b}$
}

a Senior Professorship for Medical Anthropology, Faculty of Health, Witten/Herdecke University, Herdecke, Germany;

${ }^{b}$ Chair for Theory of Medicine, Integrative and Anthroposophic Medicine, Witten/Herdecke University, Herdecke, Germany;

${ }^{\mathrm{c}}$ Institute for Integrative Medicine, Faculty of Health, Witten/Herdecke University, Herdecke, Germany;

${ }^{d}$ Department of Psychology and Psychotherapy, Witten/Herdecke University, Witten, Germany;

e Professorship for Quality of Life, Spirituality and Coping, Witten/Herdecke University, Herdecke, Germany

\section{Medical Anthropology as the Basis of Integrative and Personalized/Person-Centered Health Care}

\section{Authors: Peter Heusser, Johannes Weinzirl, Rene Ebersbach, Bettina Berger}

Today's medical concepts and the dominating understanding of human beings are essentially reductionistic: in medical theory, not only the substances and structures of the physical body are causally explained by physical laws and forces, but organismic life and conscious experiences as well. 'Life' is held for a mere product of the gene expression 'machinery', and the human mind is seen as an effect of neurobiological processes, without a reality of its own. The curricula for medical education are almost completely based on the biomedical sciences and their mechanistic model conceptions, whereas the humanities only play the marginal role of addons, not being acknowledged as integrated parts of the 'proper' and 'scientific' curriculum [1]. As a consequence, reductionism is deeply engrained into the mindset of physicians, and in consequence, 'patients are frequently unhappy with medical care because physicians fail to demonstrate humanistic qualities' [1]. The actual trend towards 'individualized' or 'personalized' medicine enhances this problem - despite its unquestionable merits - in that it focusses even more on molecular details [2] (see below the contribution to this article by Schwiegershausen et al.). Patients, however, have a deep longing for 'individualized' or 'personalized' forms of medical care which account for the whole person. This includes an 'integrative care', 'holism', 'self-activation', 'personal growth', 'well-being', and doctor-patient 'alliance' [3, 4]. Patients often miss these qualities in conventional medicine but seek them in complementary and integrative forms of care. Indeed, most complementary medical disciplines practice an explicitly personcentered approach, and the whole-system disciplines among them are usually based on systemic, multi-perspective holistic views of the human being.

An example for this is Anthroposophic Medicine (AM). AM describes body, life, soul, and spirit as four integrated but different and equally real domains of the human being [5]. On this basis, health and disease are understood as effects of harmonious or disharmonious interactions between processes of the physical body, life forces, soul, and spirit; these domains are specifically addressed in the individualized multimodal treatment strategies of AM [6]. Also, medical education in AM is systematically based on this 4-fold conception of the human being, which includes questions of patients' as well as physicians' personality development [7]. This is probably one of the reasons for the significantly higher patient satisfaction and patients' ratings of their physicians' humanistic qualities in the field of AM practices than in conventional medicine in the Swiss National Evaluation Program (PEK) [8]. This suggests that a holistic understanding of the human being and a humanistic curriculum of medical education might account better for patients' needs and expectations towards a holistic and individualized person-centered care. In other words: integrative and person-centered health care presumes a corresponding humanistic form of medical anthropology and theory of medicine.

For this reason, we established a working group for Medical Anthropology at the Chair for Theory of Medicine, Integrative and Anthroposophic Medicine as well as a Professorship for Medical Anthropology. Our 2 overall aims in research and medical education are: 1) to work out a humanistic whole-person approach to medical anthropology, based on empirical evidence and solid epistemology and 2) to appraise basic concepts of AM for their tenability and usefulness for this approach to medical anthropology. 
In research, we have worked out a seminal treatise which analyzes basic concepts of physics, chemistry, biology, neurobiology, psychology, and philosophy of mind on a thorough epistemological basis and within current debates on emergence, self-organization, and causality in the processes of matter, life, mind-body interactions, and free will. The result is a non-reductionistic medical anthropology acknowledging the emergent properties of body, life, soul, and spirit as equally real and causative entities. This corresponds exactly to the 4-fold anthropology of AM and other humanistic anthropologies of the 20th century [9].

Another group of anthropological research projects appraises Rudolf Steiner's conception of the human senses based on sensory physiology, neurobiology, and psychology. This includes the psycho-physiology of space perception [10], but especially also Steiner's unique conception of 3 social senses existing only in humans, not in animals: 1) the sense for words, 2) the sense for thoughts and 3 ) the sense for the self of another person. Steiner's central tenet is that minds, thoughts, and words of other persons are not subjective constructions as postulated by Theory-of-Mind theories, but objective perceptions. In view of the importance of social perception in person-centered care, we presently explore these social senses in a number of dissertation projects: a) the sense for words [11], b) the sense for thoughts, c) the sense for others selves by Steiner and Max Scheler, d) the sense for others selves in autism.

A third group of projects concerns Steiner's concepts of the regulation of organismic life processes, specifically his hypothesis that in addition to its known functions the spleen regulates the rhythmic integration of intestinally absorbed food into the organism. These projects include: a) an extensive review on the spleen and its functions in Rudolf Steiner's work, b) an extensive review on the relation of the spleen to gastro-intestinal functions in the current literature, and c) controlled experimental studies to test Steiner's regulation hypotheses. This began with his postulate of a postprandial expansion of the spleen volume which could be confirmed in a controlled randomized crossover study with a standardized meal and 2 different algorithms for the calculation of sonographically assessed spleen volumes [12].

A forth group of projects consists in the conceptual and empirical appraisal of the psycho-physiological development of the human individuality according to Steiner, especially with reference to the middle phase of childhood (see the contribution of Berger et al. in this issue, pp 13-15).

These and other anthropological research projects are complemented by corresponding educational programs and scientific conferences. These include: 1) weekly seminars on the epistemological and empirical evidence basis of a non-reductionist approach to medical anthropology, 2) weekly seminars on holistic anthropology and organology in the 'Integrated Curriculum for Anthroposophic Medicine' for students of medicine and psychology, 3) the yearly organization and publication of the interdisciplinary conference 'Witten Colloquia for Humanism, Medicine and Philosophy', a forum for the international discourse on basic themes of societal relevance such as humanism in medicine [13], what is spirit? [14], human individuality [15], humans versus animals [16], psycho- physiology of the senses [17], what is life?, etc. In these ways, our working group attempts to contribute to the humanistic form of medical anthropology necessary for the development of integrative and person-centered health care.

\section{Acknowledgement}

All authors are supported by the Software AG Stiftung, Darmstadt. The Stiftung has no influence on the content of their research projects and publications.

\section{Disclosure Statement}

All authors declare that there is no conflict of interest concerning this paper.

\section{References}

1 Halperin EC: Preserving the humanities in medical education. Med Teacher 2012;32:76-79.

2 Jameson JL, Longo DL: Precision medicine - personalized, problematic and promising. NEJM 2015;372:2229-2234.

3 Thiel M, Längler A, Schwermer M, et al: Person-centeredness in integrative health care and integrative medical education. Complement Med Res 2017; 24(suppl 1): doi: 10.1159/000460277.

4 Franzel B, Schwiegershausen M, Heusser P, Berger B: Individualised medicine from the perspectives of patients using complementary therapies: a meta-ethnography approach. BMC Complement Altern Med 2013;13:124.

5 Steiner R, Wegman I: Extending Practical Medicine. Fundamental Principles Based on the Science of the Spirit. London, Rudolf Steiner Press, 1996.

6 Heusser P, Berger Braun S, Bertschy M, et al: Palliative in-patient cancer treatment in an anthroposophic hospital: II Quality of life during and after stationary treatment, and subjective treatment benefits. Forsch Komplementmed 2006;13:156-166.

7 Heusser P, Scheffer C, Neumann M, et al: Towards non-reductionistic medical anthropology, medical education and practitioner-patient interaction. The example of Anthroposophic Medicine. Patient Educ Couns 2012;89:455-460.

8 Esch B, Marian F, Busato A, Heusser P: Patient satisfaction with primary care: an observational study comparing anthroposophic and conventional care. Health Qual Life Outcomes 2008;6:74.

9 Heusser P: Anthroposophy and Science. An Introduction. Frankfurt/M., Peter Lang Edition, 2016.

10 Brandl M: Raumorientierung und somatisch-psychische Aktion. Über die Beziehung von Herman A. Witkins Konzept von Raumorientierung und Rudolf Steiners Konzept von Sinnesphysiologie als Zugang zur Leib-SeeleInteraktion. Diplomarbeit (Dr. med.), Medizinische Universität Wien, 2012.

11 Peveling M: Der Sprachsinn bei Rudolf Steiner. Eine kritische Würdigung im Lichte der modernen Sprachforschung und der sozialen Neurobiologie. Dissertation, Witten/Herdecke, 2015.

12 Garnitschnig L: Postprandiale Dynamik des Milzvolumens bei gesunden Probanden. Diplomarbeit (Dr. med.), Medizinische Universität Wien, 2016.

13 Heusser P, Weinzirl J (eds): Medizin und die Frage nach dem Menschen. Würzburg, Königshausen \& Neumann, 2013.

14 Weinzirl J., Heusser P (eds): Was ist Geist? Würzburg, Königshausen \& Neumann, 2014

15 Weinzirl J, Heusser P (eds): Die menschliche Individualität - verloren und neu gesucht. Würzburg, Königshausen \& Neumann, 2015.

16 Weinzirl J, Heusser P (eds): Der Mensch, ein Tier? Das Tier, ein Mensch? Würzburg, Königshausen \& Neumann, 2016.

17 Weinzirl J, Heusser P (eds): Bedeutung und Gefährdung der Sinne im digitalen Zeitalter. Würzburg, Königshausen \& Neumann, 2017 (in print). 


\section{Body, Soul and Spirit in Psychological Research: An Enquiry into Human Individuality}

\author{
Author: Ulrich Weger
}

Integrative and personalized medicine considers various different facets of well-being, among them biological and psychological aspects. Within the academic community, however, these psychological aspects tend to be operationalized in mostly behavioral and even biological coordinates, undermining the efforts of the integrative approach to broaden the focus of enquiry. In our work, we have hence pointed out that psychological phenomena manifest in a number of ways which can be differentiated into a behavioral, an experiential, and a conceptual mode of expression [1]. The phenomenon of attention can serve as an example: on the neurobiological and behavioral levels, attention may find expression in a certain form of neuronal firing or in a particular ocular fixation pattern, among others. Moreover, attention has a qualitative side: what is it like to be in a particular state of attention as opposed to being in a state of distraction (the experiential level)? And finally, we can study patterns of lawfulness in attentional functioning that go beyond individual relevance, e.g., differences between attentional focusing versus defocusing - the conceptual level. We understand this differentiation as a reflection of what has traditionally been referred to as the levels of body, soul, and spirit (for instance in early Indian Samkya, in Greek philosophy, in Christian anthropology, in anthroposophy [2]). The neurobiological and behavioral aspects can be researched through a third-person mode of enquiry (e.g., observational or neuroimaging studies; questionnaires or interviews; etc.); the experiential (or qualia) as well as the conceptual levels, however, can be accessed in their original form only through a first-person (introspective) mode of enquiry as they become evident only in the direct immediacy of experiencing and thinking awareness.

The bodily and behavioral domain is widely acknowledged in psychological research today, but the soul (experiential) and spirit (conceptual) domains remain anathema and are studied only indirectly - via the behavioral domain. We (and others) have argued that this constitutes a reductionist view and that such an approach has emerged in the history of science not because the realms of the soul and the spirit are suspicious territory per se; but because the methods needed to study them are underdeveloped. It is because of this that we have put an emphasis on advancing a methodological approach to cultivating introspective science. While naïve introspection admittedly yields immature results and is hence more counterproductive than useful in many cases, introspection can be advanced into a more rigorous approach and then be applied meaningfully in a research context. In our work, we have begun to explore how such an introspective approach can shed light on the experiential and conceptual dimension of different psychological phenomena and have thereby sought to broaden our understanding of core concepts in psychology. The specific phenomena we have begun to address are attention, memory, and the self [1-4].

The self is a core concept in psychology that has implications for many other domains; we hence wish to focus on it here, also because this concept remains at the center of our ongoing research. In exploring one's own self and asking what its primary components or characteristics are, a range of attributes and qualities quickly come to mind: I may define myself to be a citizen of the German city of Witten, as an academic, as a son and brother, a teacher, etc. All of these are components that contribute to my socalled self-schema. Their uniting characteristic is that they constitute contents which become available in my thinking and self-reflection. Going beyond this, a cultivated form of introspection will quickly become aware of a distinction between contents and processes of thinking [5], and will in turn move on to differentiating and adding another layer to a merely content-based self-schema namely an understanding of the self in terms of a process or rather: an activity. Researching the activity side of the self is much more challenging than researching the content. Our thinking easily seeks to fill and saturate itself with (familiar) content; when working to keep it free of the common content to uncover the process side, it tends to wane to begin with (i.e., we fall asleep); or it fills itself with other available content (i.e., we get distracted). Falling asleep and getting distracted are hence frequent encounters during introspective (meditative) research. But in moments of successful concentration, such an awareness of the activity allows for an understanding of the self and of human individuality that is rather different from the mere content-based self-schema. Our attention is now directed to the source of our activity - rather than merely to the results of this activity, as is the case in normal thinking. For instance, we may try to hold an object in our mind's 'eye' (e.g., a circle) and notice the constant effort it takes to keep it vivid. With practice, however, we may reach a point where we no longer have to constantly generate the mental object in a piecemeal fashion, but where a moment of continuity is reached and we no longer experience ourselves as being separated into a subject-object duality; instead, we can experience ourselves entering into the conceptual nature or lawfulness of the phenomenon - here the circle - in our active thinking [3]. This is a momentary experience that is difficult or perhaps impossible to instantiate and maintain at our deliberate will; but the preparatory conditions are under our control - and in that sense, our methodology is in accordance with other, more behavior-oriented forms of experimentation that likewise only set the stage for an effect to appear. In researching the activity side, we also begin to notice that our traditional concepts of who we are - often developed around mostly sensory experiences - are no longer easily applicable, as the activity side is not a sensory event. This may initially be a confusing and at times even a troubling experience. Here and there, we have discovered an element of order in this chaos, however. The process of recall, for instance, is complex and elusive when initially approached introspectively. But different forms of activity in retrieving a content of memory nevertheless become noticeable with relatively little practice [4]. Our work in this direction is still very much in its infancy. But the distinction between content and activity of psychological phenomena seems to be of more general importance to us, with the latter deserving particular attention in the effort of understanding our own thinking - and ultimately ourselves - not only in terms of contents/results, but also in terms 
of the self-initiated activity that yields these results. This we see as an important facet of a personalized and integrative medical approach that speaks to the self-healing capacities through an insight into one's own activity and being. While an understanding of the self in terms of the contents places an emphasis on what 'I have become' (my job, hobbies, cultural context, etc.), an emphasis on the activity dimension opens a door towards attending to - and researching - the 'here' and 'now' of the 'I am'. We look at this as a challenging but also a most timely task, and we sense a rich potential for further work, exploring the behavioral, experiential, and conceptual dimensions of human individuality (and other psychological dimensions) in the context of Western spirituality and of Christian anthropology in more general terms [6].

\section{Acknowledgement}

This work was supported by the Dr.-Wolfgang-Raeschke-Stiftung für freies Geistesleben and the Software AG Stiftung. These institutions have no influence on the content of our research and this article.

\section{Disclosure Statement}

The author declares that there is no conflict of interest concerning this paper.

\section{References}

1 Weger UW, Wagemann J: The behavioral, experiential and conceptual dimensions of psychological phenomena: body, soul and spirit. New Ideas Psychol 2015;39:23-33.

2 Weger UW, Wagemann J: The challenges and opportunities of first-person inquiry in experimental psychology. New Ideas Psychol 2015;36:38-49.

3 Weger UW, Meyer A, Wagemann J: Exploring the behavioral, experiential, and conceptual dimensions of the self: introducing a new phenomenological approach. Eur Psychol 2016;21:180-194.

4 Weger UW, Wagemann J, Meyer A: Introspection in psychology. Its contribution to theory and method in memory research. Eur Psychol, under review.

5 White PA: Knowing more about what we can tell: 'introspective access' and causal report accuracy 10 years later. Br J Psychol 1988;79:13-45.

6 Meyer A, Wagemann J, Weger U (eds): Psychologie, Bewusstseinsforschung und Heilung im Kontext westlicher Spiritualität. Würzburg, Königshausen \& Neumann, 2016.

\section{Addressing Patients' Spiritual Needs in Health Care}

\section{Author: Arndt Büssing}

Balboni et al. [1] reported that $72 \%$ of the patients with advanced cancer in the USA felt minimally or not at all supported regarding their spiritual needs by the medical system. This might not be too surprising because one may argue that supporting these 'secondary' needs is not the task of the health care system which has to care for the 'primary needs'. However, $47 \%$ of the cancer patients did not feel supported by a religious community either [1]. This means that a large proportion of the patients may have specific unmet needs which they have no one to talk to about. When spiritual support was provided, these patients' quality of life was better [1]. This is a good argument for considering this topic in integrative and person-centered health care.

Also, in secular Germany, a majority of tumor patients wanted their medical doctor to be interested in their spiritual orientation [2]. When asked with whom German outpatients with chronic-pain diseases would like to talk about their spiritual/religious needs, $23 \%$ stated 'a chaplain/priest', $20 \%$ had no partner to talk with, and for $37 \%$ it was important to talk with their medical doctor about these needs [3]. The important fact that patients may like to talk about these needs (even when they at first do not know how to communicate this need) also means that health care professionals are confronted with specific expectations they might not be prepared for.

To more specifically address which psychosocial, existential, and spiritual needs patients with chronic diseases may have, we first provided a conceptual framework for research and clinical practice, and categorized 4 core dimensions of spiritual needs, i.e., 'connection', 'peace', 'meaning/purpose', and 'transcendence' [4]. These can be attributed to the underlying categories of 'social', 'emotional', 'existential', and 'religious'. With this background, the Spiritual Needs Questionnaire (SpNQ) [5, 6] was developed as a diagnostic tool with 27 items to measure the strength of the respective needs. Using it as a 19-item research instrument, it differentiates 4 main factors:

- Religious Needs (Cronbach's alpha $=0.92$ ), i.e., praying, participation at a religious ceremony, turn to a higher presence (i.e., God, angels, saints), reading of spiritual/religious books;

- Inner-Peace Needs (Cronbach's alpha = 0.82), i.e., wish to dwell at places of quietness and peace, finding inner peace, talking with others about fears and worries;

- Existential Needs (Cronbach's alpha $=0.82$ ), i.e., reflect previous life, dissolve open aspects in life, talk with someone about meaning in life / suffering, forgive someone from a distinct period of life;

- Giving/Generativity Needs (Cronbach's alpha $=0.74$ ), i.e., intention to solace someone, pass own life experiences to others, be assured that life was meaningful and of value.

In German patients with chronic diseases, particularly secular spiritual needs such as Inner Peace and Giving/Generativity were of importance, especially for cancer patients, while Existential Needs or Religious Needs were of lower relevance [7-9]. A similar pattern was found in predominantly areligious patients from Shanghai [10], while in catholic Poland, also Religious Needs and Existential Needs were of importance [11]. In Muslim cancer patients from Iran, Religious Needs scored highest, while Existential Needs scored lowest [12].

In patients with fibromyalgia, particularly Inner Peace and Existential Needs were weakly to moderately associated with the intention to escape from illness, with anxiety and depression, and re- 
duced quality of life, while Religious Needs did not significantly correlate with these indictors [8]. With the exception of Religious Needs, all needs indicate a lack of something seen as important. Moreover, in patients with chronic pain conditions, Religious Needs and Existential Needs were weakly to moderately related to interpreting disease as something of value or as a challenge, but also as a call for help [7]. This is a highly subjective perception of disease which may nevertheless be more prevalent in patients with specific diseases. Additional weak associations between Religious Needs and the view of illness as a threat/enemy, as well as Inner Peace / Existential Needs and the view of illness as an interruption of life would substantiate that these needs indicate patients to require further and specific support.

In (more or less) healthy elderly living in nursing and retirement homes, the respective needs scored much lower [13, 14], probably because of reduced expectations. However, one has to take into account strong regional and cultural differences, particularly with respect to the expression of Religious Needs which are of high relevance in the South of Germany, but score low in the North $[13,14]$.

The SpNQ, which is available in different languages (i.e., German, English, Italian, French, Portuguese, Danish, Polish, Chinese, Nigerian, Malaysian, Indonesian, Farsi) via SpNeeds.uni-wh.de, is currently applied also in war victims in Croatia, patients with neurological and psychiatric diseases, mothers with sick and preterm children, adolescents with chronic diseases, and in longitudinal studies enrolling persons with multiple sclerosis and women with breast cancer during chemotherapy. These data will help to complete the picture of specific needs prevalent in diverse individuals with different diseases and different regional, cultural, and religious backgrounds.

While the support of spiritual needs is well accepted in palliative care, it is not yet recognized as a topic of relevance in the early phases of diseases when patients are informed about the medical implications of their disease. In these phases, patients are left alone with their existential and spiritual needs.

Yet, supporting patients requires profound knowledge of the specific needs raised by the concrete person and thus requires communication. Patients are not 'bearer of symptoms', but individuals with a biographic background, hopes, and expectations. Spiritual care is thus primarily relation-oriented, not goal-oriented. Puchalski [15] underlined that "by creating an atmosphere of caring compassion and a willingness to be open to whatever concerns the patient, the interaction becomes focused in a patient-centered model of care'. It might be true that psychologists and pastoral workers are much better trained to address existential and religious needs, and that medical doctors and nurses neither have the necessary time nor the professional skills - but this does not argue against the fact that comprehensive health care means to care for all aspects of a person in need. This requires 'team spirit', too. All health care professionals started with the intention to help - and they all have a spiritual core competence, and all contribute with the specific competence derived from their professional qualification [16]. Not meeting patients' needs in health care means to ignore their dignity and fundamental rights, which 'are now seen as core to health care ethics' [17]

\section{Acknowledgement}

I am grateful to the Software AG Stiftung, Darmstadt, for their support. The Stiftung has no influence on the content of my research projects and publications.

\section{Disclosure Statement}

The author declares that there is no conflict of interest concerning this paper.

\section{References}

1 Balboni TA, Vanderwerker LC, Block SD, et al: Religiousness and spiritual support among advanced cancer patients and associations with end-of-life treatment preferences and quality of life. J Clin Oncol 2007;25:555-560.

2 Frick E, Riedner C, Fegg MJ, et al: A clinical interview assessing cancer patients' spiritual needs and preferences. Eur J Cancer Care 2006;15:238-243.

3 Büssing A, Michalsen A, Balzat HJ, et al: Are spirituality and religiosity resources for patients with chronic pain conditions? Pain Medicine 2009;10: 327-339.

4 Büssing A, Koenig HG: Spiritual needs of patients with chronic diseases. Religions 2010;1:18-27.

5 Büssing A, Balzat HJ, Heusser P: Spiritual needs of patients with chronic pain diseases and cancer - validation of the spiritual needs questionnaire. Eur J Med Res 2010;15:266-273.

6 Büssing A, Janko A, Kopf A, et al: Zusammenhänge zwischen psychosozialen und spirituellen Bedürfnissen und Bewertung von Krankheit bei Patienten mit chronischen Erkrankungen. Spiritual Care 2012;1:57-73.

7 Büssing A, Janko A, Baumann K, et al: Spiritual needs among patients with chronic pain diseases and cancer living in a secular society. Pain Med 2013; 14:1362-1373.

8 Offenbaecher M, Kohls N, Toussaint LL, et al: Spiritual needs in patients suffering from fibromyalgia. Evid Based Complement Alternat Med 2013; 2013:178547.

9 Höcker A, Krüll A, Koch U, Mehnert A: Exploring spiritual needs and their associated factors in an urban sample of early and advanced cancer patients. Eur J Cancer Care 2014;23:786-794.

10 Büssing A, Zhai XF, Peng WB, Ling CQ: Psychosocial and spiritual needs of patients with chronic diseases: validation of the Chinese version of the Spiritual Needs Questionnaire. J Integr Med 2013;11:106-115.

11 Büssing A, Pilchowska I, Surzykiewicz J: Spiritual Needs of Polish Patients with Chronic Diseases. J Relig Health 2015;54:1524-1542.

12 Nejat N, Whitehead L, Crowe M: Exploratory Psychometric Properties of the Farsi and English Versions of the Spiritual Needs Questionnaire (SpNQ): Religions 2016;7:84. www.mdpi.com/2077-1444/7/7/84/pdf.

13 Erichsen NB, Büssing A: Spiritual needs of elderly living in residential/nursing homes. Evid Based Complement Alternat Med 2013;2013:913247.

14 Man-Ging CI, Öven Uslucan J, Fegg M, et al: Reporting spiritual needs of older adults living in Bavarian residential and nursing homes. Ment Health Relig Cult 2015;18:809-821.

15 Puchalski CM: Addressing the spiritual needs of patients; in Angelos P (ed): Ethical Issues in Cancer Patient Care. New York, Springer, 2009, pp 79-91.

16 Büssing A, Frick E: Psychosoziale und spirituelle Bedürfnisse chronisch Kranker; in Büssing A, Surzykiewicz J, Zimowski Z (eds): Dem Gutes tun, der leidet. Spiritualität in der Behandlung und Begleitung kranker Menschen - Interdisziplinäre Perspektiven. Berlin, Heidelberg, Springer, 2015, pp 3-12.

17 Koslander T, da Silva AB, Roxberg A: Existential and spiritual needs in mental health care: an ethical and holistic perspective. J Holist Nurs 2009; 27:34-42. 


\section{The Concepts of 'Individualised' or 'Personalised' Medicine among German Experts of the Health Care System: A Sociological Discourse Analysis}

\author{
Authors: Martina Schwiegershausen, Bettina Berger, \\ Peter Heusser
}

Although 'individualisation' or 'personalisation' (synonyms) of diagnoses, treatments and prevention have become an ideal in the health care professions and the industry, the concepts for Individualised or Personalised Medicine (I/PM) have remained heterogeneous [1], and the roles ascribed to the actual target group of these concepts, the patients, have remained vague and unclear [2]. Also, research into patients' own expectations of I/PM has been largely lacking, and German ethicists have warned about this [3, 4]. However, as the clarification of I/PM concepts among the different stakeholders is a prerequisite for any strategy towards person-orientation in health care, our working group has first carried out an analysis of patients' perceptions of I/PM in a meta-ethnographic study [5]; subsequently we did the discourse analysis of I/PM concepts among professional experts as reported in this article. The aim was to contribute to the conceptual basis of the common research focus 'Integrative and Personalised/Person-Centred Healthcare' at Witten/Herdecke University and to the discourse on the topic at large.

Methodologically, our investigation first asked for the types of I/ PM concepts in the discourse among professional experts (ethicists, scientists, clinicians) in Germany and then examined the positions assigned to patients in these concepts. In order to investigate this relatively open issue, the statements of 52 experts made at congresses and conferences, published in 42 documents from 2008 to 2012, were analysed using the techniques of the Sociology of Knowledge Approach to Discourse [6] and the Grounded Theory approach [7] with recourse to medical databases. In this process, the documents were first selected according to the rules of theoretical sampling (minimum and maximum comparison, contrasting), and the relevant concept-related themes were identified in each case. Subsequently, an all-connecting explanatory interpretative paradigm was developed which illustrated the central themes of the concept in terms of content.

As a result, 2 different fields of discourse ('biomolecular' and 'integrative') were identified into which all the conceptual positions found among the 3 groups of experts could be distributed: a) the 'biomolecular' field (1. ethically oriented experts, positions: $\mathrm{n}=13$; 2. science- and research-oriented experts: $n=17$ ) and b) the integrative' field of discourse (3. clinically oriented experts: $n=22$ ). Consequently, the experts had followed either of 2 conceptual paradigms of I/PM, each of which structured a field of discourse in itself. The 'biomolecular' or 'personalised' concept was the dominant one. It was exclusively determined by objective individual biomolecular characteristics of 'unique specifications' of diseases. In contrast, the 'integrative' or 'person-oriented' concept of I/PM referred to individual needs and health care requirements of the person as a subject, i.e., to the 'unique patient' with his or her physical, psychological, social, biographical, spiritual, cultural and economic aspects, and herein integrated the contents of the 'biomolecular' concept.

With regard to the positions ascribed to patients, ethical problems of the 1-sided biomolecular concept became obvious. This concerns especially patients' uncritical identification $[8,9]$ with the burdensome responsibility and 1-sided role of avoiding or reducing potentially threatening diseases ascribed to biomolecular causes. Therefore, it is necessary to integrate the 'biomolecular'/'personalised' into the 'integrative'/'person-oriented' concepts. In the 'integrative' field of discourse, the willingness of patients to actively cope with potential risks and illness and to seek inner personal growth was conceptualised. At the same time, it became clear that it is mandatory to define the necessary comprehensive expertise of practising doctors with respect to perceiving, understanding and encouraging the subjective perspectives and potentials of the patients (patient expertise). This necessitates a training based on an integrative conception which makes explicit the different domains of individuals beyond the biomolecular level; physicians' accidental personal qualities alone are not sufficient.

In the current literature, the 2 concepts of I/PM were found in even more specified variants. As to the 'biomolecular' concept, either 'stratifying' [10] or 'personal' medicine [9] were discussed. Because biomolecular 'individualisation' is in fact usually a 'stratification', we support Schleidgen et al. [10] and propose the more accurate term 'stratifying medicine'. As to the 'integrative' concept, no agreement on a common conception was found by the time of the conclusion of this study.

So far - according to the literature -, it was only partially possible to resolve the ethically problematic risks related to the 1-sided biomolecular concept which omits more humanistic dimensions such as the psychological, social, biographical, mental and spiritual ones $[3,11,12]$. This includes the fact that the assumption of health-related individual responsibility does not on its own (sufficiently) emerge from a recourse to the biomolecular concept of I/PM [13].

In the dominant 'biomolecular' discourse, the incorporation of patients' needs and the investigation of patients' positions has not taken place yet, even 7 years after the Future Report demanded this [2]. Also, the existing conceptual knowledge from the 'integrative' field of discourse has not been considered yet in research and research funding. The correction of the 1-sided industry-driven biomolecular research by a more independent research and healthcare policy related to more encompassing health care needs in Germany has been recommended [14], and also, the inclusion of the public in deliberation processes [15], e.g. by an institutionalised participation in an integrative health care system [16, 17]. Moreover, the training of a critical and self-congruent health competence in patients has been proposed with regard to the enormous demands put on them through the quantity and complexity of stressful information referring to individual risks and a potential lack of treatment options, a point feared by ethicists $[18,19]$. This all should be embedded in an 'integrative' health care concept, resulting in the promotion of patient competence or expertise allowing for the assumption of a multifaceted but manageable health responsibility of individuals [20]. 


\section{Acknowledgement}

B.B. and P.H. are supported by the Software AG Stiftung, Darmstadt. The Stiftung has no influence on the content of their research projects and publications.

\section{Disclosure Statement}

All authors declare that there is no conflict of interest concerning this paper.

\section{References}

1 Junge M: Individualisierung, Globalisierung und Zweite Moderne; in Niederlag W, Lemke HU, Golubnitschaja O, Rienhoff O (eds): Personalisierte Medizin. Sind wir auf dem Weg zu einer individualisierten Gesundheitsversorgung? Dresden, General Hospital, 2010, pp 13-24.

2 Hüsing B, Hartig J, Bührlen B, et al: Individualisierte Medizin und Gesundheitssystem: Zukunftsreport. Berlin, Büro für Technikfolgen-Abschätzung beim Deutschen Bundestag (TAB), 2008.

3 Deutscher Ethikrat: Simultanmitschrift. Forum Bioethik. Die Medizin nimmt's persönlich. Möglichkeiten und Grenzen der Individualisierung von Diagnose und Therapie. Dtsch Ethikrat Dok 2009. www.ethikrat.org/dateien/pdf/fb_2009-06-24_simultanmitschrift.pdf (last accessed December 26, 2016)

4 Deutscher Ethikrat: Simultanmitschrift. Jahrestagung des Deutschen Ethikrates: Personalisierte Medizin - der Patient als Nutznießer oder Opfer? Dtsch Ethikrat Dok 2012. www.ethikrat.org/dateien/pdf/jahrestagung24-05-2012-simultanmitschrift.pdf (last accessed December 26, 2016).

5 Franzel B, Schwiegershausen M, Heusser P, Berger B: Individualised medicine from the perspectives of patients using complementary therapies: a meta-ethnography approach. BMC Complement Altern Med 2013;13:124.

6 Keller R: Wissenssoziologische Diskursanalyse: Grundlegung eines Forschungsprogramms, ed 3. Wiesbaden, VS Verlag für Sozialwissenschaften, 2011.

7 Strauss A, Corbin J: Grounded Theory: Grundlagen Qualitativer Sozialforschung. Weinheim, Beltz PVU, 1996.
8 Parin P: Das Ich und die Anpassungs-Mechanismen. Psyche (Stuttg) 1977; 31:481-515.

9 Danzer G: Personale Medizin, ed 1. Bern, Huber, 2012.

10 Schleidgen S, Klingler C, Bertram T, et al: What is personalized medicine: sharpening a vague term based on a systematic literature review. BMC Med Ethics 2013;14:55.

11 Woopen C: Individualisierte Medizin als zukunftsweisendes Leitbild; in Schumpelick V, Vogel B (eds): Medizin nach Maß: Individualisierte Medizin - Wunsch und Wirklichkeit. Beiträge des Symposiums vom 9. bis 12 . September 2010 in Cadenabbia. Freiburg, Verlag Herder, 2011, pp 94-110.

12 Kollek R: Individualisierung der Medizin: medizintheoretische und gesellschaftliche Implikationen eines mehrdeutigen Leitbilds. Z Evid Fortbild Qual Gesundhwes 2012;106:40-45.

13 Langanke M, Fischer T, Erdmann P, Brothers KB: Gesundheitliche Eigenverantwortung im Kontext Individualisierter Medizin. Ethik Med 2013;25: 243-250.

14 Vollmann J: Persönlicher - besser - kostengünstiger? Kritische medizinethische Anfragen an die 'personalisierte Medizin'. Ethik Med 2013;25: 233-241.

15 Kettner M: Ethische und kommunikative Bedeutung der 'personalisierten Medizin'. Gesundheitswesen 2014;76:e51-e56.

16 Geraedts M: Integrative und personenzentrierte Gesundheitsversorgung aus der Perspektive des Gesundheitssystems. Gesundheitswesen 2014;76: e74-e78.

17 Schleidgen S, Marckmann G: Kriterien für eine ethisch angemessene Priorisierung individualisierter Therapiemaßnahmen. Gesundheitswesen 2014; 76:e57-e64.

18 Berger B, Sladek U, Gerlach A, et al: 'Wissen macht stark und gesund' Kompetenztraining zur Stärkung von kritischer Gesundheitsbildung: Inhalte, Methoden und erste Ergebnisse; in Berger B (ed): Raum für Eigensinn: Ergebnisse eines Expertentreffens zur Patientenkompetenz. Essen, KVC Verlag, 2011, pp 165-188.

19 Bischof M: Von der Patientenkompetenz zur Gesundheitskompetenz; in Berger B (ed): Raum für Eigensinn: Ergebnisse eines Expertentreffens zur Patientenkompetenz. Essen, KVC Verlag, 2011, pp 235-253.

20 Heusser P, Neugebauer E, Berger B, Hahn E: Integrative und personalisierte Gesundheitsversorgung - Forderungen für ein zeitgemäßes Gesundheitssystem. Gesundheitswesen 2012;75:151-154. 